\title{
String-pulling in the Goffin's cockatoo (Cacatua goffiniana)
}

\author{
Birgit Wakonig ${ }^{1} \cdot$ Alice M. I. Auersperg ${ }^{2} \cdot$ Mark O'Hara $^{2}$ (D)
}

Accepted: 6 December 2020 / Published online: 22 January 2021

(C) The Author(s) 2021

\begin{abstract}
Goffin's cockatoos, a parrot species endemic to the Tanimbar Islands in Indonesia, demonstrate remarkable cognitive skills across various technical tasks. These neophilic extractive foragers explore objects with their beak and feet, and are skilled in several modes of tool use. In this study, we confronted the animals for the first time with a vertical string-pulling setup, including a set of classic and novel controls. Nine of the 12 subjects, two of which were subadults, immediately interacted with the singlestring task, with seven individuals successfully obtaining the reward on their very first attempt. Four different double string discrimination tests with varying spatial relations were used to assess the Goffin's cockatoos' apprehension of basic physical task properties. We found significant differences in performance between the respective experimental conditions, as well as the development of side biases. The results suggest that while the birds seem to consider simple cause-effect relationships, there is no evidence for a mental representation of the causal mechanisms underlying the string-pulling tasks, as subjects failed the crossed strings condition out of immediate sight. Finally, we provide suggestions on improving the methodology, and discuss our findings in regard to the Goffin's cockatoo's ecology.
\end{abstract}

Keywords Physical cognition $\cdot$ Problem solving $\cdot$ Perception $\cdot$ Mental representation $\cdot$ Sensorimotor skills

The string-pulling paradigm is an important benchmark test in comparative cognition that has been used to address various and often overlapping cognitive abilities, such as Gestalt perception, means-end understanding, causal reasoning, and insight (e.g., Köhler, 1925; Piaget, 1952; Taylor et al., 2010; Wang et al., 2019; Wasserman, Nagasaka, Castro, \& Brzykcy, 2013). As the basic task is highly versatile, a multitude of string-pulling task versions are still widely applied to address various questions in multiple species, ranging from birds to mammals (including humans), and even invertebrates (Alem et al., 2016; Brown, 1990; Buttelmann, Carpenter, Call, \& Tomasello, 2008; Chapman \& Weiss, 2013; Jacobs \& Osvath, 2015; Plotnik, Lair, Suphachoksahakun, \& De Waal, 2011; Range, Möslinger, \& Virányi, 2012; Riemer, Müller, Range, \& Huber, 2014).

Birgit Wakonig

birgit.wakonig@chello.at

Mark O’Hara

mark.ohara@vetmeduni.ac.at

1 University of Vienna, Althahnstraße 14, 1090 Vienna, Austria

2 Messerli Research Institute, University of Veterinary Medicine Vienna, Veterinaerplatz 1, 1210 Vienna, Austria
The basic setup of the string-pulling paradigm can easily be adjusted into different versions, depending on the target species and the purpose of the study. For example, the string orientation can be chosen to appear horizontal or vertical; when testing parrots, predominantly vertical string-pulling setups have been used (see Jacobs \& Osvath, 2015), while horizontal arrangements have largely been employed with mammals, invertebrates and other bird species (e.g., Dücker \& Rensch, 1977; Hofmann, Cheke, \& Clayton, 2016; Obozova \& Zorina, 2013; Taylor, Knaebe, \& Gray, 2012' but see Auersperg, Gajdon, \& Huber, 2009; de MendonçaFurtado \& Ottoni, 2008; van Horik \& Emery, 2016, for exceptions in testing parrot species). Other methodological variations include the alteration of string number and pattern. Tests with a single string are used to ascertain whether subjects possess the necessary sensorimotor skills to acquire the food reward at the end of the string (Altevogt, 1953). Multiple strings are used to investigate means-end understanding, for which four criteria have been proposed that must be met: (1) goal-directedness, (2) no proximity errors (choosing the string closest to the reward), (3) flexible solutions, and (4) no dependence on immediate feedback (Jacobs \& Osvath, 2015). Using multiple strings can establish whether the pulling behavior is goal-directed or intrinsically rewarded (Hofmann et al., 2016), while introducing more complex string patterns, such as slanted, elongated, crossed, or double-crossed, can control 
for proximity errors, as well as allowing the investigation into the roles of visual and proprioceptive feedback (Hofmann et al., 2016; Schuck-Paim, Borsari, \& Ottoni, 2009; Taylor et al., 2010).

A more recent addition to the classic string-pulling tests has been the introduction of visually restricted conditions (Gaycken, Picken, Pike, Burman, \& Wilkinson, 2019; Molina, Cullell, \& Mimó, 2019; Taylor et al., 2010). One way to restrict the view of the reward during pulling is to insert an occluder between the string's anchor point and the reward (Molina et al., 2019; Taylor et al., 2010). In a study involving New Caledonian crows (Corvus moneduloides), one individual solved the task, while overall results were inconclusive after several trials (Taylor et al., 2010). Similarly, African grey parrots (Psittacus erithacus) did not solve the visually restricted conditions (Molina et al., 2019), and thus both studies indicate that subjects relied on proprioceptive feedback rather than more sophisticated cognitive processing. An alternative method is a task setup that requires subjects to pull a string in a downward facing direction in order to move the reward upward, by leading the strings over a pivot (Heinrich \& Bugnyar, 2005). In order to limit visibility, a platform is installed for the subjects to stand on, preventing immediate visual access to the end of the string (Gaycken et al., 2019). After initial exposure to a standard string-pulling paradigm, in which the string was pulled simply upwards, several ravens (Corvus corax) successfully transferred their previous experience to the counterintuitive action of pulling downward. Therefore, the authors argued that some functional understanding, beyond mere operant conditioning, must have been employed in this task (Heinrich \& Bugnyar, 2005). However, green-winged macaws (Ara chloroptera) failed to solve a similar transfer (Gaycken et al., 2019).

One of the first studies to systematically investigate stringpulling in parrots was an experiment conducted with four naïve African grey parrots by Irene Pepperberg (2004), to whom this special issue is dedicated (see Fischel, 1936; Funk, 2002; Rensch \& Dücker, 1977, for other early studies). In her study, Pepperberg (2004) found that while language-naïve individuals would spontaneously perform the steps necessary for coordinated pulling, two language-trained grey parrots vocally requested the reward from the human experimenter, which was suggested as possibly representing a form of understanding of certain task properties. This study focused on the parrots' spontaneity in pulling a single vertical string provided from a $\mathrm{T}$ stand and proposed that the language-trained subjects tried to engage in communication as a problem-solving strategy, thus exhibiting a transfer of behavioral patterns from one situation to another, which is considered a hallmark of intelligent behavior. Whereas the parrots who were not language trained successfully performed the string-pulling action sequence of pulling, stepping, and repeating, so as to obtain the reward at the other end of the single string and thus expressed spontaneity in the single string-pulling task.

Various psittacids have since been studied in different string-pulling studies (Table 1; see Jacobs \& Osvath, 2015). While most parrots seem to be able to solve the basic stringpulling task, the crossed-string condition in particular seems to pose great difficulties for the majority of parrots. Only kea (Nestor notabilis), spectacled parrotlets (Forpus conspicillatus), galahs (Eolophus roseicapilla), and African grey parrots seem to be able to, at least partially, solve this condition (Krasheninnikova, 2013; Krasheninnikova, Bräger, \& Wanker, 2013; Molina et al., 2019; Werdenich \& Huber, 2006). However, the view of the strings was only fully restricted for the African grey parrots (Molina et al., 2019).

Goffin's cockatoos (Cacatua goffiniana) are feeding generalists (Mioduszewska et al., 2019; O'Hara et al., 2019), originally endemic to the Tanimbar Islands in Indonesia. Studies under controlled laboratory conditions have highlighted this species' proficiency in several technical tasks, requiring abilities that have been argued as prerequisites to succeed in string-pulling (see Auersperg, Teschke, \& Tebbich, 2017; Jacobs \& Osvath, 2015): They react flexibly and sensitively to small changes in their environment (Auersperg, Borasinski, Laumer, \& Kacelnik, 2016; Auersperg, Kacelnik, \& von Bayern, 2013; Auersperg, Laumer, \& Bugnyar, 2013), they seem to attend to several functional aspects while solving physical tasks (Auersperg et al., 2013), including the relations between objects (Habl \& Auersperg, 2017), and, most notably, they exhibit some degree of means-end apprehension during the manufacture and use of tools (Auersperg, Szabo, von Bayern, \& Kacelnik, 2012; Auersperg et al., 2014; Auersperg, Köck, Pledermann, O'Hara, \& Huber, 2017; Laumer, Bugnyar, Reber, \& Auersperg, 2017). However, despite the extensive research in regard to their physical cognition, this species has not been previously tested on any of the classic variations of the string-pulling paradigm. Our aim was to close this gap by providing naïve Goffin's cockatoos with a classical string-pulling setup with a single string, as well as versions using perpendicular, crossed, shortened, and coiled strings, in addition to adopting a slightly modified design to control for visual access.

Taking into consideration other parrot species' past performances (above), we expect that Goffin's cockatoos possess the basic sensorimotor skills required to spontaneously solve a single string condition without any visual restriction. To investigate whether the cockatoos could act in a goaldirected manner, we used two strings of the same length with only one string rewarded (perpendicular condition) to see whether they chose the baited string immediately and above chance expectation, or if they pulled randomly, either due to a lack of attention to the end of the strings or a desire to explore the strings. In order to see whether the subjects followed a spatial proximity rule, we used two rewarded strings, with 
Table 1 Twenty-eight parrot species have been tested in various vertical string-pulling patterns; here, we report only the performance in conditions also conducted in the present study

\begin{tabular}{|c|c|c|c|c|c|c|c|c|}
\hline Species & $\mathrm{N}$ & $\mathrm{Si}$ & $\mathrm{Pe}$ & $\operatorname{Pr}$ & Pc & $\mathrm{Cr}$ & Reference & $\mathrm{G} / \mathrm{I}$ \\
\hline \multirow{3}{*}{ African Grey Parrots (Psittacus erithacus) } & $3 c$ & $\mathrm{~S}$ & $\mathrm{~S} / \mathrm{F}$ & & & $\mathrm{S} / \mathrm{F}$ & Molina et al., 2019 & \\
\hline & 1c & $S$ & $\mathrm{~S}$ & & & $\mathrm{~F}$ & $\begin{array}{l}\text { Krasheninnikova, Bovet, Busse, } \\
\text { \& Péron, } 2012\end{array}$ & 1 \\
\hline & $4 \mathrm{c}$ & $\mathrm{S} / \mathrm{F}$ & & & & & Pepperberg, 2004 & $\mathrm{I}$ \\
\hline Blue-and-gold macaw (Ara ararauna) & 2c & $\mathrm{S}$ & & & & & Fischel, 1936 & 1 \\
\hline Blue-fronted amazon (Amazona aestiva) & $2 c$ & $\mathrm{~S}$ & $\mathrm{~S}$ & & & $\mathrm{~F}$ & Schuck-Paim et al., 2009 & $\mathrm{I}$ \\
\hline Blue-throated macaw (Ara glaucogularis) & 2c & $S$ & $S$ & & & $\mathrm{~F}$ & Krasheninnikova et al., 2012 & G \\
\hline Budgerigar (Melopsittacus undulatus) & $5 c$ & $S$ & $\mathrm{~F}$ & & & $\mathrm{~S} / \mathrm{F}$ & Krasheninnikova et al., 2012 & G \\
\hline Cockatiel (Nymphicus hollandicus) & $\begin{array}{c}10 \\
c\end{array}$ & $\mathrm{~S}$ & $\mathrm{~S} / \mathrm{F}$ & $\mathrm{S} / \mathrm{F}$ & & $\mathrm{F}$ & Krasheninnikova, 2013 & G \\
\hline Eclectus parrot (Eclectus roratus) & $\begin{array}{c}10 \\
c\end{array}$ & $\mathrm{~S}$ & $\mathrm{~F}$ & $\mathrm{~F}$ & & $\mathrm{~F}$ & Krasheninnikova, 2014 & G \\
\hline Galah (Eolophus roseicapilla) & $6 c$ & $\mathrm{~S}$ & $\mathrm{~S} / \mathrm{F}$ & $\mathrm{S} / \mathrm{F}$ & & $\mathrm{S} / \mathrm{F}$ & Krasheninnikova, 2013 & G \\
\hline $\begin{array}{l}\text { Greater Patagonian conure (Cyanoliseus } \\
\text { patagonus) }\end{array}$ & $3 c$ & $\mathrm{~S}$ & $\mathrm{~F}$ & & & $\mathrm{~S}$ & Krasheninnikova et al., 2012 & G \\
\hline Greater Vasa Parrot (Coracopsis vasa) & $\begin{array}{c}10 \\
c\end{array}$ & $\mathrm{~S}$ & $S$ & $\mathrm{~F}$ & & $\mathrm{~S}$ & Krasheninnikova, 2014 & G \\
\hline \multirow[t]{2}{*}{ Green-winged macaw (Ara chloroptera) } & 4c & $S$ & & & & $\mathrm{~F}$ & $\begin{array}{l}\text { Ortiz, Maxwell, Krasheninnikova, } \\
\text { Wahlberg, \& Larsen, } 2019\end{array}$ & G \\
\hline & $\begin{array}{c}10 \\
c\end{array}$ & $\mathrm{~S} / \mathrm{F}$ & & & & & Gaycken et al., 2019 & 1 \\
\hline Hyacinth macaw (Anodorhynchus hyacinthius) & $4 \mathrm{c}$ & $\mathrm{S}$ & $\mathrm{S}$ & & & $\mathrm{F}$ & Schuck-Paim et al., 2009 & 1 \\
\hline Illiger's macaw (Ara maracana) & 2c & $\mathrm{S}$ & $\mathrm{F}$ & & & $\mathrm{S} / \mathrm{F}$ & Krasheninnikova et al., 2012 & G \\
\hline Kaka (Nestor meridionalis) & $\begin{array}{l}30 \\
w\end{array}$ & $S / F$ & & & & & Loepelt, Shaw, \& Burns, 2016 & 1 \\
\hline Kea (Nestor notabilis) & 7c & $\mathrm{S} / \mathrm{F}$ & $\mathrm{S}$ & & & $\mathrm{S} / \mathrm{F}$ & Werdenich \& Huber, 2006 & G \\
\hline Lear's macaw (Anodorhynchus leari) & $4 c$ & $\mathrm{~S}$ & $\mathrm{~S}$ & & & $\mathrm{~F}$ & Schuck-Paim et al., 2009 & 1 \\
\hline Monk parakeet (Myiopsitta monachus) & 7c & $\mathrm{S}$ & $\mathrm{F}$ & $\mathrm{F}$ & & $\mathrm{F}$ & Krasheninnikova, 2014 & G \\
\hline Orange-winged Amazon (Amazona amazonica) & $\begin{array}{c}32 \\
c\end{array}$ & $\mathrm{~S} / \mathrm{F}$ & $\mathrm{S}$ & $\mathrm{S}$ & & $\mathrm{F}$ & $\begin{array}{l}\text { Krasheninnikova \& Schneider, } \\
2014\end{array}$ & G \\
\hline \multirow[t]{2}{*}{ Peach-faced lovebird (Agapornis roseicollis) } & $\begin{array}{c}15 \\
c\end{array}$ & $S$ & $S$ & & & $S$ & Krasheninnikova, 2014 & G \\
\hline & $6 c$ & $\mathrm{~S}$ & $\mathrm{~S}$ & & & $\mathrm{~S}$ & Krasheninnikova et al., 2012 & G \\
\hline Peach-fronted conures (Eupsittula aurea) & 4c & $\mathrm{S}$ & & & & $\mathrm{F}$ & Ortiz et al., 2019 & G \\
\hline Rainbow Lorikeet (Trichoglossus haematodus) & $\begin{array}{c}13 \\
\mathrm{c}\end{array}$ & $S$ & $S$ & & & $\mathrm{~F}$ & Krasheninnikova et al., 2013 & G \\
\hline Red-spectacled Amazon (Amazona pretrei) & 2c & $\mathrm{S}$ & S & & & $\mathrm{F}$ & Krasheninnikova et al., 2012 & G \\
\hline Senegal parrot (Poicephalus senegalus) & $\begin{array}{c}12 \\
c\end{array}$ & $S$ & $S$ & $\mathrm{~F}$ & & $\mathrm{~S}$ & Krasheninnikova, 2014 & G \\
\hline Slender-billed cockatoo (Cacatua tenuirostris) & $6 c$ & $\mathrm{~S}$ & $\mathrm{~S}$ & & & $\mathrm{~F}$ & Krasheninnikova et al., 2012 & G \\
\hline Spectacled parrotlet (Forpus conspicillatus) & $\begin{array}{c}22 \\
\mathrm{c}\end{array}$ & $S$ & $S$ & & & $S$ & Krasheninnikova et al., 2013 & G \\
\hline Sulfur-crested cockatoo (Cacatua galerita) & $3 c$ & $\mathrm{~S}$ & $\mathrm{~S}$ & & & $\mathrm{~F}$ & Krasheninnikova et al., 2013 & G \\
\hline Sun parakeet (Aratinga solstitialis) & 2c & $\mathrm{S}$ & & & & & Krasheninnikova et al., 2012 & G \\
\hline $\begin{array}{l}\text { Thick-billed parrot (Rhynchopsitta } \\
\text { pachyrhyncha) }\end{array}$ & 1c & $S$ & $S$ & & & $\mathrm{~F}$ & Krasheninnikova et al., 2012 & 1 \\
\hline
\end{tabular}

Note. $N=$ number of individuals (c = captive, $\mathrm{w}=$ wild); $\mathrm{Si}=$ single string (baseline); $\mathrm{Pe}=$ perpendicular; $\mathrm{Pr}=$ proximity; $\mathrm{Pc}=$ perception; $\mathrm{Cr}=\mathrm{crossed} ; \mathrm{S}$ = success; F = failed; G/I indicates a study's success determined on group level or individual level; highlighted in grey are studies employing visual limitations

one shorter than the other (proximity condition), expecting them to choose the shorter (and therefore closer) string over the longer string if they were using such a rule. Visual access to the string was prevented in this condition to keep the setup 
consistent between tests. This setup allowed for testing of the proximity rule, in contrast to using the more commonly slanted or crossed strings as these test setups would only allow for proximity rule testing in case the leading of the string could be perceived. Random choice in this condition would suggest a lack of sensitivity to spatial proximity, whereas choosing the longer string above chance could indicate that the action of string-pulling may in itself be intrinsically rewarding (e.g., exploration or play). To see if the cockatoos were making choices based on proprioceptive rather than visual feedback, the baited string was left long enough to be coiled onto the apparatus floor, and the unbaited string was both weighted and shorter (coiled condition). If this heavier string was repeatedly chosen, it would indicate that attention was focused on proprioceptive feedback, as the coiled string did not offer any perceptive weight resistance during the first pulling actions. It was expected that individuals would choose the rewarded coiled string over the unrewarded standard-length string with weight resistance if their choice was based on visual rather than on proprioceptive feedback. The chosen setup of the coiled condition shed light on the perceptive abilities of Goffin's cockatoos when presented with both strings long and coiled but one of these having a broken connection, as neither of the strings would provide any perceptual weight resistance within the first pulling actions. Finally, in order to investigate representation, the subjects were presented with two crossed strings, with only one rewarded (crossed condition). Due to the board acting as a visual occluder, subjects could only inspect the crossed string setup while perching in front of the apparatus before the start of each trial, but not from above while performing the pulling behavior. Therefore, if the birds were able to maintain a mental representation of the crossing during their decision-making process, we would expect the rewarded string to be chosen immediately and more than expected by chance; on the contrary, choices based on visual proximity would result in the pulling of the nonrewarded string. Random choices could indicate that contradicting information (immediate visual feedback vs. previous experience) resulted in conflicting motivation, or the adoption of cognitively less demanding, yet beneficial, strategies, such as side biases. Finally, if the proximity, coiled, or crossed conditions were intrinsically rewarding, we would expect to find no preferential or above chance choices.

\section{Methods}

\section{Subjects}

This study was conducted at Goffin Lab Goldegg of the Messerli Research Institute in Austria, which houses a group of 16 hand-reared Goffin's cockatoos (see Table 2) in a flock with an indoor and outdoor area (indoor: $45 \mathrm{~m}^{2}, 3-6-\mathrm{m}$ height; outdoor: $150 \mathrm{~m}^{2}, 3-6-\mathrm{m}$ height). The birds had ad libitum access to fresh water and food (variety of food pellets, fruits, vegetables, and mineral supplements). Nine individuals participated in the double string conditions and an additional three individuals participated in the single string test $(n=12)$.

Cashew nuts were only available as a reward during test sessions, in which the cockatoos participated voluntarily. All subjects had CITES certificates and were registered at the district's administrative animal welfare bureau (Bezirkshauptmannschaft St. Pölten, Schmiedgasse 4-6, A-3100, St. Pölten, Austria). These housing conditions were following the Austrian Federal Act on the Protection of Animals (Animal Protection Act- $\$ 24$ Abs. $1 \mathrm{Z} 1$ and 2; $\$ 25$ Abs. 3-TSchG, BGBl. I Nr. 118/2004 Art. 2). As our tests were appetitive, noninvasive, and based exclusively on behavioral observations, they were not classified

Table 2 Detailed subject information: names, sex, and hatch date of the 12 participating cockatoos and information about participation in single and all conditions with two strings, as well as the number of trials required to reach a criterion of 10 consecutive correct choices during training

\begin{tabular}{|c|c|c|c|c|c|}
\hline Name & Sex & Hatch date & Single string test & Training trials & Double string test \\
\hline Figaro & Male & 2007 & Yes & 110 & Yes \\
\hline Fini & Female & 2007 & Yes & 310 & Yes \\
\hline Pipin & Male & 2008 & Yes & 250 & Yes \\
\hline Heidi & Female & 2010 & Yes & 250 & Yes \\
\hline Zozo & Male & 2010 & Yes & 40 & Yes \\
\hline Kiwi & Male & 2010 & Yes & 250 & Yes \\
\hline Konrad & Male & 2010 & Yes & - & No \\
\hline Dolittle & Male & 2011 & Yes & 310 & Yes \\
\hline Mayday & Female & 2011 & Yes & - & No \\
\hline Jane & Female & 2017 & Yes & 100 & Yes \\
\hline Titus & Male & 2017 & Yes & 190 & Yes \\
\hline Irene & Female & 2017 & Yes & - & No \\
\hline
\end{tabular}


as animal experiments under the Austrian Animal Experiments Act (§2. Federal Law Gazette No. 501/1989). Although research at Goffin Lab Goldegg has mainly focused on physical cognition, only three individuals had some prior experience in a double string-pulling task, all other subjects were string-pulling naïve. The subadults Jane, Titus, and Irene were introduced to a double string-pulling task at an early ontogenetic stage by providing them with vertical and horizontal strings (length $=25 \mathrm{~cm}$ ). One string had an object connected to one end, whereas the other string did not. In the course of a 24-weeks-development test, the three birds managed to successfully pull in the baited string within three consecutive trials.

\section{Apparatus}

The apparatus consisted of a cubed wire cage that enabled subjects to pull the strings through holes in the top. The strings were inserted starting from the perch through a board with two holes (see Fig. 1) to ensure a restricted view of the strings by the birds. The subjects could view the inside of the apparatus from their starting position in front of it.

Customary jute strings with a diameter of $2 \mathrm{~mm}$ were used, and they varied in length depending on the chosen condition.

Cube-shaped containers with a side length of $2.3 \mathrm{~cm}$ and an open top, to enable a clear view of the contents, were attached to the ends of the strings. The container holding the reward was colored blue, while the empty container remained transparent. A shim was glued to the bottom of both containers to increase their weights to $10 \mathrm{~g}$.

The subjects were trained to differentiate between the two cubes and to prefer the blue colored one over the transparent one, by offering each subject both cubes at the same time on a white table without any attached string; visual access to the inside of the cubes was prevented. The cockatoos had to choose the blue cube over the transparent cube five times in a row to ensure an association had been established.

\section{Procedure}

The cockatoos were habituated to the apparatus in groups of five to eight birds by providing small pieces of pecan nuts and parrot baby mash. Later, they were individually encouraged with a food reward to sit on the perch on top of the box. Four different double-string conditions were used to test different cognitive abilities described in this section, plus a single-string condition to test for spontaneous string-pulling. The cockatoos were able to view the cubes from the perch in front of the apparatus as well as through the holes on top at all times. Nevertheless, their view of the strings was obstructed from the top of the apparatus in all double-string conditions. The view of the reward within the container, however, was not restricted.
Table 3 details the criteria for a trial being determined as successful in both the single-string and double-string setups; for all four double-string conditions, the same criteria had to be met.

\section{Single string}

The cockatoos' sensorimotor abilities and spontaneity were tested by offering them one baited $70-\mathrm{cm}$ long string in an apparatus without the board on top that would restrict their view into the box.

\section{Double-string test}

\section{Perpendicular condition (baseline condition)}

Two strings of the same length of $70 \mathrm{~cm}$ were used, one of them baited and the other one not (see Fig. 1a). This condition was for testing goal-directedness and, if the birds continued to choose at random in the beginning, they were trained to succeed before starting the next condition as listed in Table 2, Training Trials column. This was done because the perpendicular condition served as baseline and a precondition to start the other three double string conditions (see below) in order to control for their basic understanding of a double-string task and therefore their goal-directedness in their further decisions and actions in the experiment.

\section{Proximity condition}

Two strings of different lengths, one $70 \mathrm{~cm}$ and the other 35 $\mathrm{cm}$, were used, both of which were baited with pieces of cashew nuts (see Fig. 1b). The subjects' susceptibility to proximity was tested in this condition.

\section{Coiled condition}

Two strings of different lengths were used, one which was $100 \mathrm{~cm}$ with $25 \mathrm{~cm}$ of its end coiled on the bottom of the box and baited, and one that was $70-\mathrm{cm}$ long, which was not baited (see Fig. 1c). The purpose of this condition was to test for a potential reliance on proprioceptive or visual feedback (e.g., whether the cockatoos kept pulling the visibly baited coiled string without feeling the weight of the reward container for the first two to three pulling occurrences). The number of pulling actions depended on their body length.

\section{Crossed condition}

Two $85-\mathrm{cm}$ long strings were led into a crossed position by a ring-shaped piece of plastic (see Fig. 1d). As the crossing of the strings was visually restricted by the top board, this condition tested the subjects' potential to act on a previously 


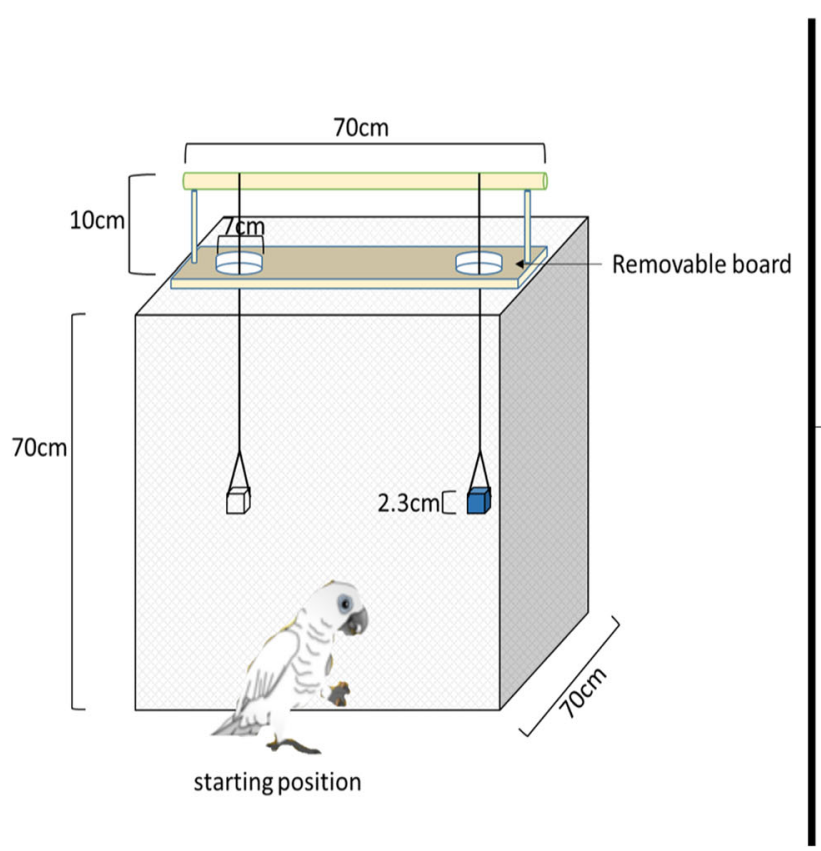

Fig. 1 Illustration of the apparatus used with measurements (left). Arrangement of strings in different conditions (right) with the blue cube representing rewarded containers and the white cube containers without a reward. Arrows show the insertion direction of the string. a Perpendicular (baseline) condition: two strings both $70 \mathrm{~cm}$ in length. b Proximity condition: two strings, $70-\mathrm{cm}$ and $35-\mathrm{cm}$ long, both baited. c Coiled

acquired mental representation of the setup, as opposed to relying on immediate visual feedback.

\section{Training procedure}

\section{Single string}

After successful habituation to the apparatus, the birds were tested for their spontaneity with the single-string condition. The cockatoos had to succeed in pulling the string in three sessions of 12 trials each before performing the two string training sessions for the baseline condition (perpendicular).

In case a bird did not succeed in pulling the $70-\mathrm{cm}$ string, the string was shortened to $40 \mathrm{~cm}$. After five consecutive successful trials, the string was set to $55 \mathrm{~cm}$ for another five consecutive successful trials before setting the string back to $70 \mathrm{~cm}$ for three sessions of 12 trials each.

\section{Training procedure: perpendicular (baseline)}

To ensure that individuals were sufficiently familiar with the affordances of the visual restriction, we presented the perpendicular condition, including the board installed on top of the apparatus, as part of the training. In case the birds did not successfully choose the baited string for 10 consecutive trials within 16 sessions, both strings were shortened to $40 \mathrm{~cm}$, and the board on top of the apparatus, which was restricting the a)
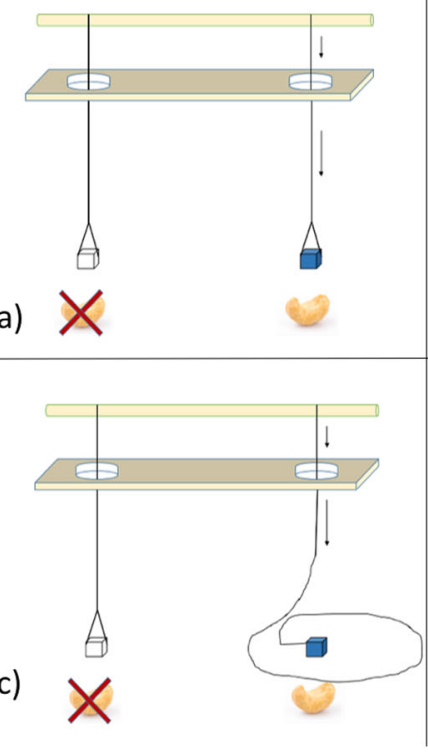

b)
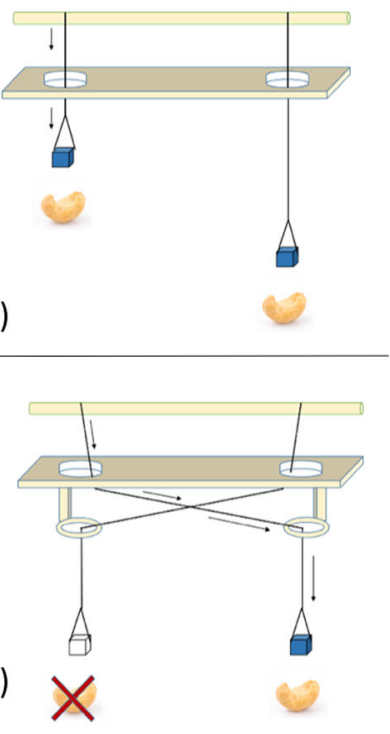

condition: two strings $70-\mathrm{cm}$ and $100-\mathrm{cm}$ long, the longer one baited and being coiled on the bottom of the box. d Crossed condition: two strings, both $85 \mathrm{~cm}$ in length, held in a crossed position by ring-shaped pieces of plastic; note that visual access to the crossing of the strings from above is prevented by the board

subjects' view of the course of the strings, was removed. The birds performed 10 trials before the strings were expanded to $70 \mathrm{~cm}$ for another 10 trials, still without a board on top of the apparatus.

The next step was a session of 10 trials with $70-\mathrm{cm}$ strings after the board was installed on top of the box, which allowed the subjects to see the containers at the end of the strings for another 10 trials. In case the subjects did not succeed after this session, the procedure was repeated.

Training for the perpendicular condition was complete after 10 consecutive successful trials with $70-\mathrm{cm}$ strings and the board installed on top of the apparatus, restricting the subjects' view from above and only allowing sight of the containers at the end of the strings (see Table 2 for the number of trials until this criterion was met).

\section{Testing}

All tests were started at the front of the box with a clear view of the task arrangement for the subject. The experimenter started every trial verbally with a start signal, after which the birds voluntarily jumped or flew on the top of the apparatus.

The maximum duration of a trial was 2 minutes. In case a subject did not start the trial within this timeframe, it was considered unsuccessful due to time-out. If the bird started to work on the trial but did not succeed in pulling up the string with the reward successfully within 2 minutes, the duration 
Table 3 Detailed information on the condition, requirement, and criteria to be met determining a trial as successful for the single-string and all doublestring conditions

\begin{tabular}{|c|c|c|}
\hline Condition & Requirement & Criteria to be met \\
\hline \multirow[t]{2}{*}{1 string } & $\begin{array}{l}\text { Spontaneous } \\
\text { pulling }\end{array}$ & Spontaneously pull a string of $\geq 40 \mathrm{~cm}$ without prior training within 5 minutes \\
\hline & Start of next trial & As soon as the setup has been prepared (pause between trials not necessarily required but permitted) \\
\hline \multirow[t]{6}{*}{2 strings } & End of trial & $\leq 2$ minutes from the start signal for individuals not beginning to solve the task (waiting) \\
\hline & & $\leq 5$ minutes from the start signal for individuals working to solve the task (working) \\
\hline & Choice of string & $\begin{array}{l}\text { Correct string must be chosen first (only a touch of the unrewarded string first without any pull with beak-foot-beak } \\
\text { sequence permitted) }\end{array}$ \\
\hline & Pulled string & Correct string must be pulled until the blue colored container is touched by the subject's beak \\
\hline & Reward taken & $\begin{array}{l}\text { In cases where the reward was lost due to the pulling efforts, it was provided by the experimenter as soon as the blue } \\
\text { colored container was touched by the subject's beak (in the proximity condition, the one on the short string) }\end{array}$ \\
\hline & Start of next trial & As soon as the setup had been prepared (pause between trials not necessarily required but permitted) \\
\hline
\end{tabular}

was extended to 5 minutes before the trial was considered unsuccessful.

Nine cockatoos participated in 12 sessions, each consisting of 12 trials. Each condition involving two strings was provided three times per session. The order of the conditions within each session was randomized for every bird. The laterality of the rewarded strings was semirandomized per trial for every subject, to prevent the rewarded string being presented on the same side more than five times in a row within the same session.

Testing in the single string condition was limited to a maximum of 3 days per week between November 11, 2018, and December 1, 2018; the individuals received one session per testing day. Testing in the

double-string conditions was limited to a maximum of 4 days per week between September 29, 2019, to February 13, 2020. Most individuals performed one session per testing day. However, no more than two sessions per individual were given on the same testing day.

During testing, the experimenter wore mirrored sunglasses to prevent gaze following. All trials were recorded using a camcorder.

\section{Analysis}

The analysis was performed using $\mathrm{R}$ Version 3.6.3 (R Core Team, 2018). We examined the performance of all cockatoos per condition using a binomial mixed model, including condition, side of rewarded string, trial, and session as main effects, and subject as a random factor with the lme4 package (Bates, Mächler, Bolker, \& Walker, 2015). Model selection was performed by stepwise model reduction based on the Akaike's information criterion (AIC). Post hoc analysis of differences between conditions was carried out with Tukey pairwise comparisons employing the package multcomp (Hothorn, Bretz, \& Westfall, 2008). To correct for multiple comparisons, results were adjusted using a Bonferroni correction. Individual performance, as well as the side of choice within each condition, was assessed using one-sided binomial tests to evaluate whether the probability of the observed performances was greater or less than would be predicted by chance.

\section{Results}

\section{Single-string condition}

Nine out of 12 cockatoos started to pull a single string of $70 \mathrm{~cm}$ after some exploratory actions (nibbling the string or the perch); eight of them immediately performed the targeted action of pulling with the beak, holding the string with the foot, and repeating these behaviors (pull-hold-pull) without prior training. The other three individuals obtained the reward during their first attempt pulling a string of $40 \mathrm{~cm}$ instead of 70 $\mathrm{cm}$. One individual, Pipin, in his first attempt with a $40-\mathrm{cm}$ string, once took some steps sideways, holding the string in his beak until the reward could be obtained, similar to the pulling technique of some cockatiels and kea (Krasheninnikova, 2013; Werdenich \& Huber, 2006). However, as of the second trial, he switched to the pullhold-pull technique, which continued for the remainder of the trials. Seven of the nine individuals who initially pulled the 70-cm string successfully obtained the reward in their very first attempt. Both Dolittle and Titus explored the string and tried to pull it with their beak, but did not hold it with their foot to obtain the desired reward, while Figaro did not even approach the string at all in his initial $70-\mathrm{cm}$ string trial. Using the 40-cm string setup, all three immediately performed the pull-hold-pull sequence successfully. The subadults Irene, Jane, and Titus, as well as one adult, Zozo, pulled the string while sitting on the perch on top of the box in their initial 
attempts, while all other individuals preferred to remain sitting on the wire grid. However, during the course of the experiment, all of the Goffin's cockatoos ended up pulling the string from the wire grid instead of the perch, though their technique remained the same regardless of their position.

\section{Double-string conditions}

Three of the 12 birds that participated in the single string condition dropped out of the subsequent double string tests, leaving nine subjects for the remaining conditions.

The binomial generalized linear mixed model revealed no influence of trial (GLMM). $\chi^{2}(11)=14.09, p=0.23$, or session $(\mathrm{GLMM}), \chi^{2}(11)=6.04, p=0.87$, on the choice of strings. However, we did find a significant effect of condition $($ GLMM $), \chi^{2}(3)=481.78, p<.001$, on successful performance. Post hoc analysis revealed significant differences between all levels of condition (see Table 4).

Analysis of the number of correct choices using the binomial test on an individual level (see Fig. 2) revealed that each subject chose the baited string significantly above chance in the perpendicular condition, whereas every individual chose the unbaited string in the crossed condition significantly above chance. Two individuals, Jane and Dolittle, refused to work in the crossed condition and did not attempt to pull any of the two strings throughout all sessions. Only one individual, Jane, chose the reward on the shorter string significantly above chance in the proximity condition, with all other subjects showing no preference for a particular string. Six out of nine subjects chose the correct string in the coiled condition significantly more often than predicted by chance, while two individuals performed at chance levels. One individual, Titus, exhibited a tendency $(p=.067)$ to pull on the short, but unrewarded, string more often.

Furthermore, our model highlighted a significant effect of reward position on the number of correct choices (GLMM), $\chi^{2}(1)=16.99, p<.001$. We performed individual binomial testing of the side selected irrespective of reward position (see

Table 4 Results of the pairwise Tukey post hoc test comparing all levels of condition; error-probability has been adjusted for multiple comparisons employing the Bonferroni-correction method

\begin{tabular}{llllll}
\hline Condition & $\beta$ & $S E$ & $z$ value & $p$ & Sig. \\
\hline Crossed vs. coiled & -2.9423 & 0.2121 & -13.872 & $<.001$ & $* * *$ \\
Perpendicular vs. coiled & 1.2005 & 0.2215 & 5.420 & $<.001$ & $* * *$ \\
Proximity vs. coiled & -0.7348 & 0.1695 & -4.335 & $<.001$ & $* * * *$ \\
Perpendicular vs. crossed & 4.1427 & 0.2510 & 16.507 & $<.001$ & $* * *$ \\
Proximity vs. crossed & 2.2074 & 0.2042 & 10.808 & $<.001$ & $* * *$ \\
Proximity vs. perpendicular & -1.9353 & 0.2155 & -8.979 & $<.001$ & $* * *$ \\
Signif. code & $.001 * * *$ & & & & \\
\hline
\end{tabular}

Fig. 3). Only one individual, Titus, exhibited significantly more pulling behavior on the right side in the perpendicular condition. Similarly, only one bird, Kiwi, was observed to pull more often on a particular side in the crossed condition (right), and only one subject, Heidi, chose the right side more often in the coiled condition. However, seven out of nine individuals pulled the string significantly more often on one particular side in the proximity condition, and only two individuals showed no side preference. Three individuals (Zozo, Pipin, and Jane) exhibited a left-side bias, and four individuals (Kiwi, Fini, Figaro, and Dolittle) chose the right string significantly above chance levels.

\section{Discussion}

We aimed to test naïve captive Goffin's cockatoos on a specific set of conditions using the string-pulling paradigm (see below). Considering that seven out of 12 subjects solved the single-string condition on their first trial, we may conclude that they are capable of immediately employing the appropriate set of requisite motor actions (Werdenich \& Huber, 2006). Pulling in out of reach items might be part of their foraging repertoire in their natural habitat.

The pulling technique used by the cockatoos differed substantially from previous observations in some other parrot species, such as cockatiels (Krasheninnikova, 2013) and grey parrots (Pepperberg, 2004). While the former succeeded by sliding, flipping, looping, side walking, or turning (Krasheninnikova, 2013), the Goffin's cockatoos' technique seemed more similar to that used by galahs (Krasheninnikova, 2013) and keas (Werdenich \& Huber, 2006) — namely, pulling the string in an upright position. However, the galahs pulled the string with their feet (Krasheninnikova, 2013), whereas the Goffin's cockatoos used their beaks for the pull-up action (see Fig. 4). Moreover, the kea performed the step-on method to hold the string in position during repetitive pulling bouts, while the Goffin's cockatoos alternated between pulling with their beak and holding the string up with one foot to prevent it from falling back down. The Goffin's cockatoos have highly developed beak-foot coordination up to the point of being able to open a bolt with their feet (Auersperg et al., 2013). Although two kea used the technique of grasping and pulling the string with the foot (Werdenich \& Huber, 2006), they did not grab the string with the beak and hold it in place with their foot, as observed with the Goffin's cockatoos. However, the upright pull, as described as being used by some kea (Werdenich \& Huber, 2006), was also performed by Goffin's cockatoos.

Using the double-string conditions, we hoped to more closely examine the four criteria of means-end understanding as formulated by Jacobs and Osvath (2015): (1) goal- 


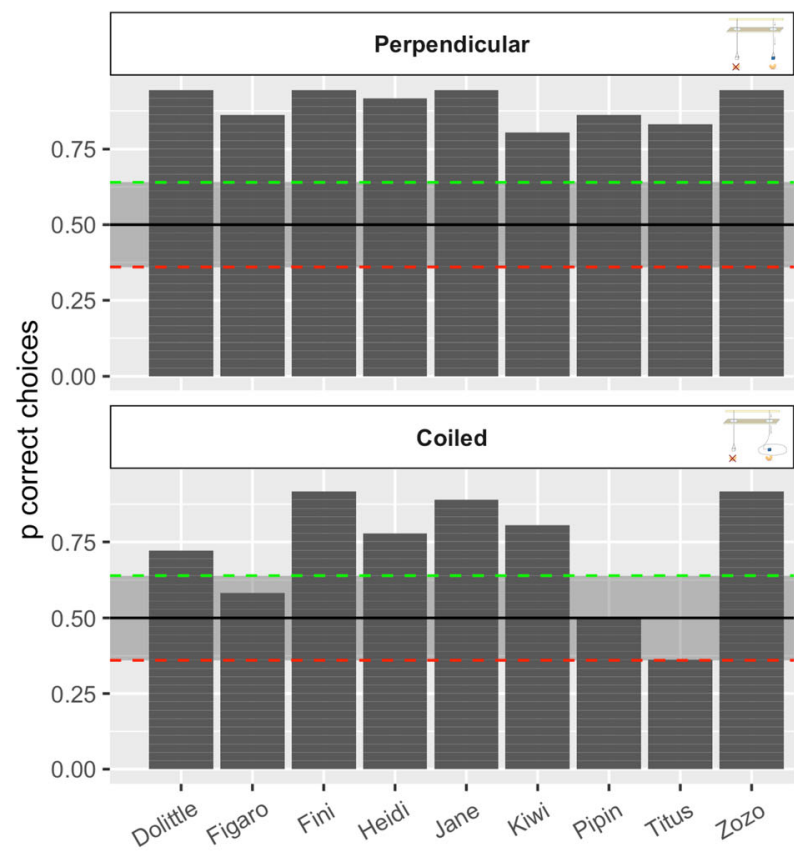

Subject
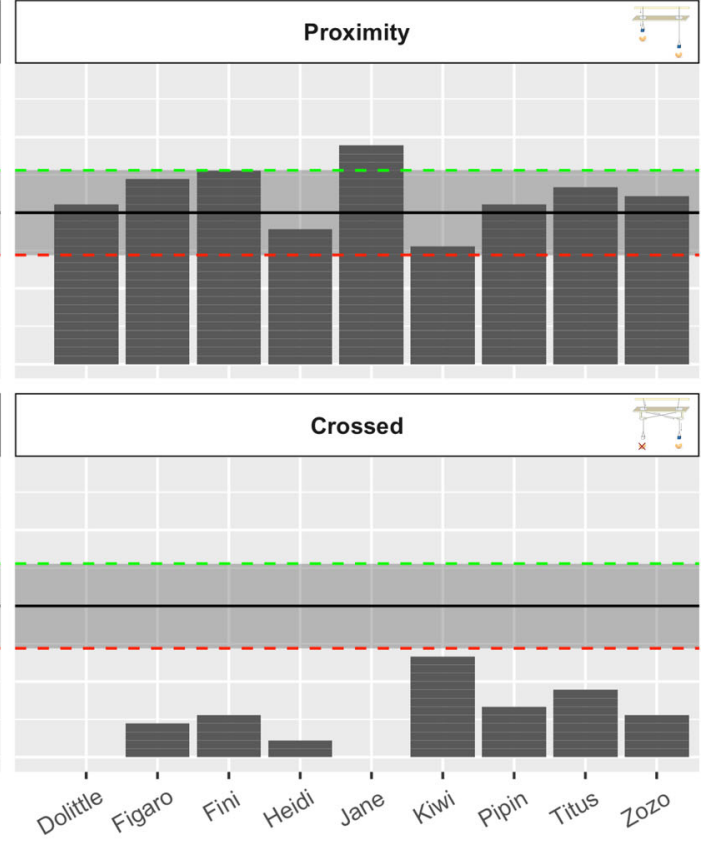

significantly less (red; probability of success $=0.36, p=.066$ ) and more (green; probability of success $=0.6, p=.066$ ) correct choices than predicted by chance. (Color figure online)

decision based on the proximity of the string's end, the success of the majority of birds in the coiled condition allows us to exclude that there is a predominant reliance on proprioceptive feedback for solving this task.

The final condition involved crossed strings that were out of immediate sight during pulling. As all individuals performed significantly below chance expectation, we presume that Goffin's cockatoos most likely focused on the immediate visual feedback provided through the holes of the board on top of the box. They did not seem to memorize and retrieve the visual information they received while sitting in front of the box once they were lifted up to the top. However, it is noteworthy that one individual (Pipin) spontaneously solved the crossed condition correctly in his very first trial and throughout the first session, though his efficiency decreased substantially during the experiment. This supports previous findings showing that Goffin's cockatoos based their choice between two tool locations on task information gathered prospectively (briefly seeing a task before the two tools), but did not manage to apply similar task information gathered retrospectively (briefly seeing the tools before the task; Beinhauer, Bugnyar, \& Auersperg, 2019). Subjects might have perceived the affordances of the crossed strings, but did not consider it a task before they had access to the strings, and thus were not sufficiently motivated to attend to the setup. Repeating this condition with additional naïve individuals without visual restriction and evaluating early trial performance might thus provide further insights into the formation of mental representations of the setup. 


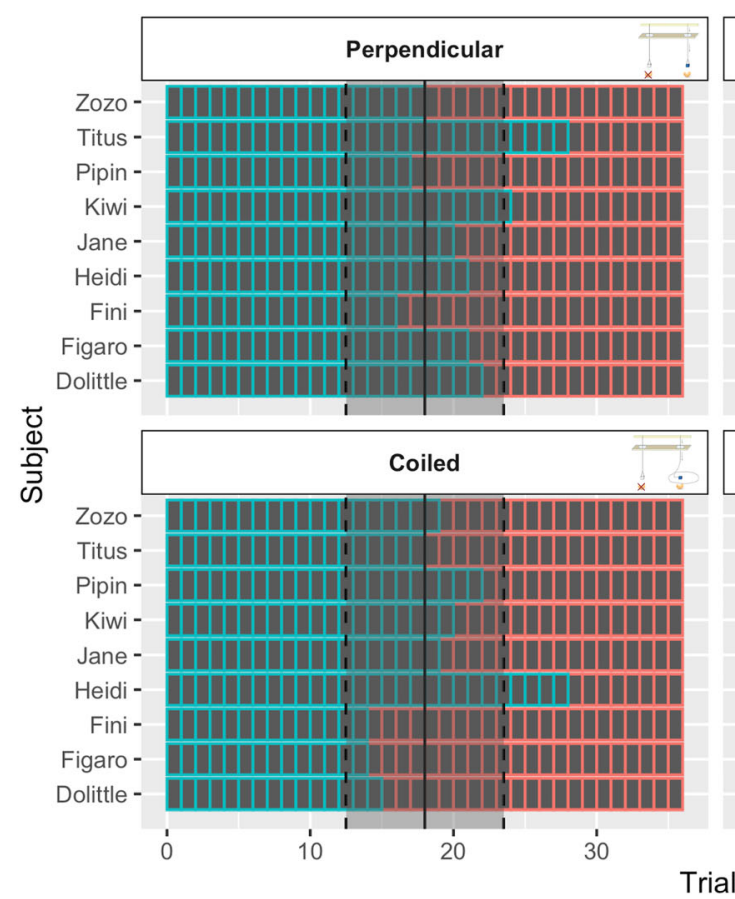

Fig. 3 The observed proportion of sides chosen by each individual shown within each condition. Solid black lines and grey bounding boxes indicate a nonsignificant choice of one side over another; dashed lines demarcate

Difficulties in the crossed-string condition are consistent with the results of most similar studies with other parrot species (see Jacobs \& Osvath, 2015, and Table 1 for a review). Nevertheless, again, we must highlight that, unlike other previous successful parrot studies, in our study the crossing of strings was visually blocked by the top board of the apparatus during the string-pulling action. Thus, the crossing could have only been perceived before accessing the perch, and any correct choice would have had to be made based on a mental representation of the task configuration. As none of the individuals changed their strategy after unsuccessful trials, reliance on visual proximity dominated over any potential short-term learning effect. This may be explained by an overtraining or
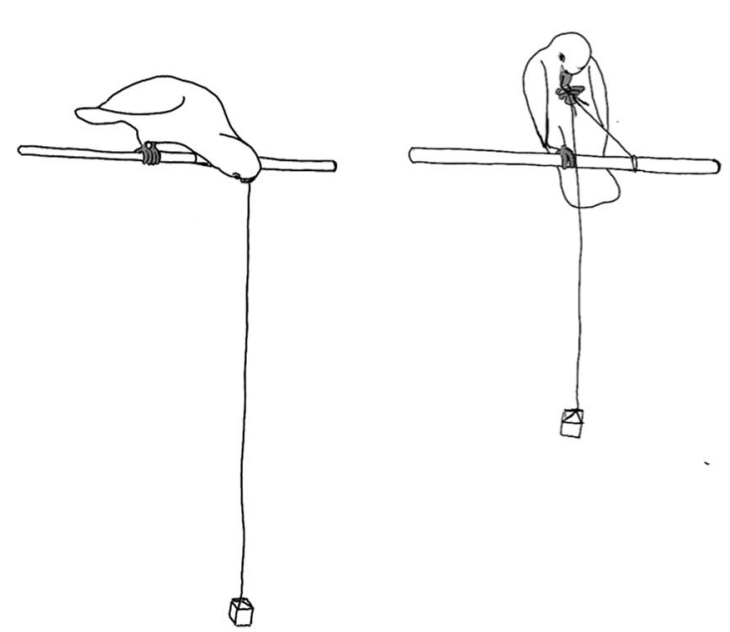
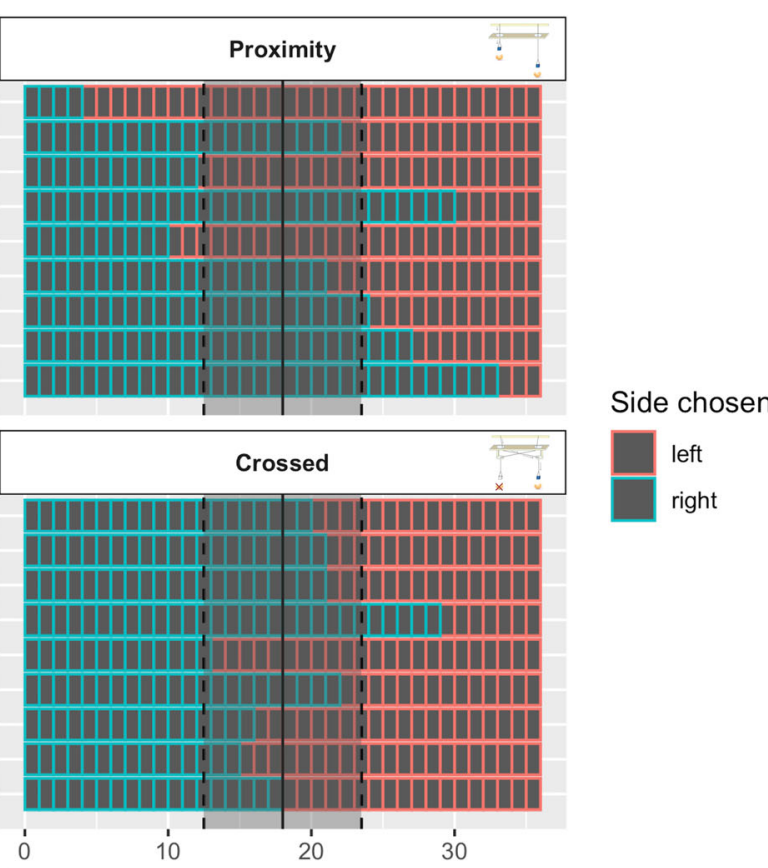

strings significantly chosen more often on the right side (red) or on the left side (turquoise). (Color figure online)

carryover effect (Díaz-Uriarte, 2002; Mandler \& Goldberg, 1975) from the training phase. The individuals likely learned to predominantly focus on the configuration from the top, rather than paying attention to the arrangement form the starting position. As we found no learning effect for the cockatoos, neither within one session nor from one session to another, we think it likely that the birds reexamine the task setup prior to every trial and did not conclude a solution from past trials or sessions. Future replication of this study without prior training may be informative if reliance on direct visualization was acquired during the training stage.

Despite trying to control for the development of a side bias by pseudorandomizing the position of the reward, several
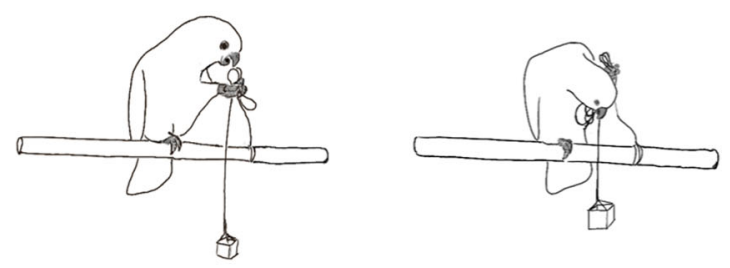

Fig. 4 String-pulling sequence as performed by subject Irene (Illustration by Mark O’Hara) 
individuals exhibited side preferences. Such a strategy can be beneficial as they are rewarded in 50\% of the cases (Gagne, Levesque, Nutile, \& Locurto, 2012; Holekamp, Swanson, \& Van Meter, 2013; Jacobs \& Osvath, 2015). It has been shown that individual birds developed side biases in different conditions, indicating cognitive difficulties with specific task properties (O'Hara, Auersperg, Bugnyar, \& Huber, 2015). Side biases in the proximity condition may also suggest that the effort of pulling a longer string was not sufficiently cumbersome.

While the abilities required for string-pulling, such as Gestalt perception, causal reasoning and means-end understanding, have been argued to play a role in extractive foraging, nest building, and tool use (reviewed in Auersperg et al., 2017), the ecological relevance for a wild animal to perform a string-pulling task is rarely discussed; to our knowledge, a direct example where this skill would be applied in nature has not been described so far for parrots. Halsey, Bezerra, and Souto (2006) discussed observations of wild common marmosets (Callithrix jacchus) attempting to access out-ofreach fruit, and place string-pulling capacities within a foraging context for primates. As for parrots, Magat and Brown (2009) showed that species that used their feet for manipulation during foraging were more likely to succeed in a stringpulling task. Similarly, Krasheninnikova (2013) discussed intricate foot-beak coordination as a potential adaptation to the foraging ecology. Exploratory play during ontogeny was considered as another factor that contributed to developing capacities involved in string-pulling on a proximate level. We agree that most likely play (on a proximate) and foraging ecology (on the ultimate level) have allowed parrots to develop the skills necessary to solve the string-pulling paradigm. Here, we also provide a direct example from the wild in which string-pulling skills may be adaptive.

In their natural habitat, the small Tanimbar archipelago in the Moluccan region of Indonesia, the Goffin's cockatoos feed on wild maracuja (Passiflora foetida; Mioduszewska et al., 2019; O’Hara et al., 2019). These flowering plants produce small individual fruit pods growing on long vines and represent a highly valuable foraging source to the wild cockatoos. The birds mostly prefer the ripe yellow fruit that may grow alongside unripe green fruit on vines, which can grow up to five meters long (Witt \& Luke, 2017). Multiple vines often occur together in shrubs and form entangled accumulations. To reach the prized fruit, the bids have to either descend on these vines or pull them up. This observation provides a direct example for ecological relevance of basic sensorimotor skills. As two of the subjects in this study were tested as juveniles and showed competence for string-pulling, we expect this skill to develop during early stages of their life. This is in line with findings in ravens that plateaued at Stage 5 in object permanence trials within the first 6 month during ontogeny (Bugnyar, Stöwe, \& Heinrich, 2007).
Our results indicate that Goffin's cockatoos possess the basic motor-sensory means required to succeed in the stringpulling task (Jacobs \& Osvath, 2015). While subjects most likely relied on immediate visual feedback in the current study, these birds may still possess the relevant capacities to understand means-end relations and to base their choices on mental representations. However, such cognitively demanding mechanisms might be easily overruled by simpler ones (O'Hara et al., 2015), especially provided prior reinforcement. Therefore, further studies without prior training and additional conditions including visual access during choice in the crossed condition might help to resolve this ambiguity. Furthermore, a comparison of string-pulling abilities of captive and wild Goffin's cockatoos would be beneficial to better understand whether cognitive abilities underlying stringpulling tasks develop with natural experience, and to examine the role of string-pulling in a socioecological context.

Acknowledgments We would like to thank Michael and Daniel Wakonig for their help with apparatus construction and Jennifer Colbourne for proofing the manuscript. We would also like to thank two anonymous reviewers, and especially Debbie Kelly, for their valuable comments and help improving the manuscript.

Open practices statements None of the data or materials for the experiments reported here is available, and none of the experiments was preregistered.

Funding Open Access funding provided by University of Veterinary Medicine Vienna. Funding for this study was provided by the Vienna Science and Technology Fund (WWTF) project "The Innovation Problem: Factors Influencing Innovative Tool Use in Human Infants and Cockatoos" (CS18-023) and the Austrian Science Fund (FWF) as part of the project "Technical Innovativeness in the Goffin's Cockatoo" (P 29075) awarded to A.A. M.O. is grateful for funding received by the Austrian Science Fund (FWF) to conduct the project "Cognitive Ecology of Goffin's Cockatoos (Cacatua goffiniana)” (J 4169-B29).

Open Access This article is licensed under a Creative Commons Attribution 4.0 International License, which permits use, sharing, adaptation, distribution and reproduction in any medium or format, as long as you give appropriate credit to the original author(s) and the source, provide a link to the Creative Commons licence, and indicate if changes were made. The images or other third party material in this article are included in the article's Creative Commons licence, unless indicated otherwise in a credit line to the material. If material is not included in the article's Creative Commons licence and your intended use is not permitted by statutory regulation or exceeds the permitted use, you will need to obtain permission directly from the copyright holder. To view a copy of this licence, visit http://creativecommons.org/licenses/by/4.0/.

\section{References}

Alem, S., Perry, C. J., Zhu, X., Loukola, O. J., Ingraham, T., Søvik, E., \& Chittka, L. (2016). Associative mechanisms allow for social learning and cultural transmission of string pulling in an insect. PLoS Biology, 14(10), 1-28. https://doi.org/10.1371/journal.pbio. 1002564 
Altevogt, R. (1953). Über das "Schöpfen" einiger Vogelarten [About the "scooping" of some bird species]. Behaviour, 6(2), 147-152.

Auersperg, A., Teschke, I., \& Tebbich, S. (2017). Physical cognition and tool use in birds. In C. ten Cate \& S. D. Healy (Eds.), Avian cognition (pp. 163-183). Cambridge: Cambridge University Press. https://doi.org/10.1017/9781316135976.010

Auersperg, A. M.I., Borasinski, S., Laumer, I., \& Kacelnik, A. (2016). Goffin's cockatoos make the same tool type from different materials. Biology Letters, 12(11), 2-5. https://doi.org/10.1098/rsbl. 2016.0689

Auersperg, A. M. I., Gajdon, G. K., \& Huber, L. (2009). Kea (Nestor notabilis) consider spatial relationships between objects in the support problem. Biology Letters, 5(4), 455-458.

Auersperg, A. M. I., Szabo, B., von Bayern, A. M. P., \& Kacelnik, A. (2012). Spontaneous innovation in tool manufacture and use in a Goffin's cockatoo. Current Biology 22(21), R903-R904.

Auersperg, A. M. I., Kacelnik, A., \& von Bayern, A. M. P. (2013). Explorative learning and functional inferences on a five-step means-means-end problem in Goffin's cockatoos (Cacatua goffini). PLoS ONE, 8(7), e68979. https://doi.org/10.1371/journal.pone. 0068979

Auersperg, A. M. I., von Bayern, A. M. I., Weber, S., Szabadvari, A., Bugnyar, T., \& Kacelnik, A. (2014). Social transmission of tool use and tool manufacture in Goffin cockatoos (Cacatua goffini). Proceedings of the Royal Society B: Biological Sciences 281(1793). https://doi.org/10.1098/rspb.2014.0972.

Auersperg, A. M. I., Köck, C., Pledermann, A., O’Hara, M., \& Huber, L. (2017). Safekeeping of tools in Goffin's cockatoos, Cacatua goffiniana. Animal Behaviour, 128, 125-133. https://doi.org/10. 1016/j.anbehav.2017.04.010

Auersperg, A. M. I., Laumer, I. B., \& Bugnyar, T. (2013). Goffin cockatoos wait for qualitative and quantitative gains but prefer "better" to “more". Biology Letters, 9(3), 20121092. https://doi.org/10.1098/ rsbl.2012.1092

Bates, D., Mächler, M., Bolker, B., \& Walker, S. (2015). Fitting Linear mixed-effects models using $\{1 \mathrm{me} 4\}$. Journal of Statistical Software, 67(1), 1-48. https://doi.org/10.18637/jss.v067.i01

Beinhauer, I., Bugnyar, T., \& Auersperg, A. M. I. (2019). Prospective but not retrospective tool selection in the Goffin's cockatoo (Cacatua goffiniana). Behaviour, 156(5/8), 633-659. https://doi.org/10.1163/ 1568539X-00003515

Brown, A. L. (1990). Domain-specific principles affect learning and transfer in children. Cognitive Science, 14(1), 107-133. https://doi. org/10.1016/0364-0213(90)90028-U

Bugnyar, T., Stöwe, M., \& Heinrich, B. (2007). The ontogeny of caching in ravens, Corvus corax. Animal Behaviour. https://doi.org/10.1016/ j.anbehav.2006.08.019

Buttelmann, D., Carpenter, M., Call, J., \& Tomasello, M. (2008). Rational tool use and tool choice in human infants and great apes. Child Development, 79(3), 609-626. https://doi.org/10.1111/j.14678624.2008.01146.x

Chapman, K. M., \& Weiss, D. J. (2013). Pulling to scale: Motor planning for sequences of repeated actions by cotton-top Tamarins (Saguinus oedipus). Journal of Experimental Psychology: Animal Behavior Processes, 39(2), 180-186. https://doi.org/10.1037/a0031775

de Mendonça-Furtado, O., \& Ottoni, E. B. (2008). Learning generalization in problem solving by a blue-fronted parrot (Amazona aestiva). Animal Cognition, 11(4), 719-725.

Díaz-Uriarte, R. (2002). Incorrect analysis of crossover trials in animal behaviour research. Animal Behaviour, 63(4), 815-822. https://doi. org/10.1006/anbe.2001.1950

Fischel, W. (1936). Die Gedächtnisleistungen der Vögel [The memory of birds]. Zeitschrift Für Züchtung. Reihe B, Tierzüchtung Und Züchtungsbiologie Einschließlich Tierernährung, 36(1), 13-38. https://doi.org/10.1111/j.1439-0388.1936.tb00081.x
Funk, M. (2002). Problem solving skills in young yellow-crowned parakeets (Cyanoramphus auriceps). Animal Cognition 5(3),167176.

Gagne, M., Levesque, K., Nutile, L., \& Locurto, C. (2012). Performance on patterned string problems by common marmosets (Callithrix jacchus). Animal Cognition, 15(5), 1021-1030. https://doi.org/10. 1007/s10071-012-0511-0

Gaycken, J., Picken, D. J., Pike, T. W., Burman, O. H. P., \& Wilkinson, A. (2019). Mechanisms underlying string-pulling behaviour in green-winged macaws. Behaviour, 156(5/8), 619-631. https://doi. org/10.1163/1568539X-00003520

Habl, C., \& Auersperg, A. M. I. (2017). The keybox: Shape-frame fitting during tool use in Goffin's cockatoos (Cacatua goffiniana). PLoS ONE, 12(11), 1-19. https://doi.org/10.1371/journal.pone.0186859

Halsey, L. G., Bezerra, B. M., \& Souto, A. S. (2006). Can wild common marmosets (Callithrix jacchus) solve the parallel strings task? Animal Cognition, 9, 229-233 https://doi.org/10.1007/s10071006-0016-9

Heinrich, B., \& Bugnyar, T., (2005). Testing Problem Solving in Ravens: String-Pulling to Reach Food. Ethology 111(10),962-976

Hofmann, M. M., Cheke, L. G., \& Clayton, N. S. (2016). Western scrubjays (Aphelocoma californica) solve multiple-string problems by the spatial relation of string and reward. Animal Cognition. https://doi. org/10.1007/s10071-016-1018-x

Holekamp, K. E., Swanson, E. M., \& Van Meter, P. E. (2013). Developmental constraints on behavioural flexibility. Philosophical Transactions of the Royal Society B: Biological Sciences, 368(1618). https://doi.org/10.1098/rstb.2012.0350

Hothorn, T., Bretz, F., \& Westfall, P. (2008). Simultaneous inference in general parametric models. Biometrical Journal, 50(3), 346-363. https://doi.org/10.1002/bimj.200810425

Jacobs, I. F., \& Osvath, M. (2015). The string-pulling paradigm in comparative psychology. Journal of Comparative Psychology, 129(2), 89-120. https://doi.org/10.1037/a0038746

Köhler, W. (1925). The mentality of apes. New York: Harcourt, Brace.

Krasheninnikova, A. (2013). Patterned-string tasks: Relation between fine motor skills and visual-spatial abilities in parrots. PLOS ONE, 8(12), e85499. https://doi.org/10.1371/journal.pone.0085499

Krasheninnikova, A. (2014). Physical cognition in parrots: A comparative approach. Hamburg: University of Hamburg Press.

Krasheninnikova, A., Bovet, D., Busse, U., \& Péron, F. (2012, June). The parrot and the string: Means-end understanding in twelve psittacid bird species. Poster presented at the ASAB Interdisciplinary Workshop: Physical Cognition and Problem Solving, Birmingham, UK.

Krasheninnikova, A., Bräger, S., \& Wanker, R. (2013). Means-end comprehension in four parrot species: Explained by social complexity. Animal Cognition, 16(5), 755-764. https://doi.org/10.1007/s10071013-0609-Z

Krasheninnikova, A., \& Schneider, J. M. (2014). Testing problemsolving capacities: Differences between individual testing and social group setting. Animal Cognition. https://doi.org/10.1007/s10071014-0744-1

Laumer, I. B., Bugnyar, T., Reber, S. A., \& Auersperg, A. M. I. (2017). Can hook-bending be let off the hook? Bending/unbending of pliant tools by cockatoos. Proceedings of the Royal Society B: Biological Sciences, 284(1862), 20171026. https://doi.org/10.1098/rspb.2017. 1026

Loepelt, J., Shaw, R. C., \& Burns, K. C. (2016). Can you teach an old parrot new tricks? Cognitive development in wild kaka (Nestor meridionalis). Proceedings of the Royal Society B: Biological Sciences, 283(1832). https://doi.org/10.1098/rspb.2015.3056

Magat, M., \& Brown, C. (2009). Laterality enhances cognition in Australian parrots. Proceedings of the Royal Society B: Biological Sciences. https://doi.org/10.1098/rspb.2009.1397 
Mandler, J. M., \& Goldberg, J. (1975). Changes in response to S+ and Sduring acquisition and overtraining of simultaneous discriminations in rats. Animal Learning \& Behavior, 3(3), 226-234. https://doi.org/ 10.3758/BF03213436

Mason, W. A., Harlow, H. F., \& Reuping, R. R. (1959). The development of manipulatory responsiveness in the infant rhesus monkey. Journal of Comparative and Physiological Psychology, 52(5), 555-558. https://doi.org/10.1037/h0041898

Mioduszewska, B. M., O'Hara, M. C., Haryoko, T., Auersperg, A. M. I., Huber, L., \& Prawiradilaga, D. M. (2019). Notes on ecology of wild Goffin's cockatoo in the late dry season with emphasis on feeding ecology. TREUBIA, 45, 85-102. https://doi.org/10.14203/treubia. $\mathrm{v} 45 \mathrm{i} 0.3706$

Molina, A. B. C., Cullell, T. M., \& Mimó, M. C. (2019). String-pulling in African grey parrots (Psittacus erithacus): Performance in discrimination tasks. Behaviour, 156(5/8), 847-857. https://doi.org/10. 1163/1568539X-00003511

O'Hara, M., Auersperg, A. M. I., Bugnyar, T., \& Huber, L. (2015). Inference by exclusion in Goffin cockatoos (Cacatua goffini). PLoS ONE, 10(8), e0134894. https://doi.org/10.1371/journal.pone. 0134894

O’Hara, M., Mioduszewska, B., Haryoko, T., Prawiradilaga, D. M., Huber, L., \& Auersperg, A. (2019). Extraction without tooling around-The first comprehensive description of the foraging- and socio-ecology of wild Goffin's cockatoos (Cacatua goffiniana). Behaviour, 156(5/8), 661-690. https://doi.org/10.1163/1568539X00003523

Obozova, T. A., \& Zorina, Z. A. (2013). Do great grey owls comprehend means-end relationships? International Journal of Comparative Psychology, 26(3), 197-201.

Ortiz, S. T., Maxwell, A., Krasheninnikova, A., Wahlberg, M., \& Larsen, O. N. (2019). Problem solving capabilities of peach-fronted conures (Eupsittula aurea) studied with the string-pulling test. Behaviour, 156(5/8), 815-846. https://doi.org/10.1163/1568539X-00003539

Pepperberg, I. M. (2004). "Insightful" string-pulling in grey parrots (Psittacus erithacus) is affected by vocal competence. Animal Cognition, 7(4), 263-266. https://doi.org/10.1007/s10071-0040218-y

Piaget, J. (1952). The origins of intelligence in children. Madison: International Universities Press.

Plotnik, J. M., Lair, R., Suphachoksahakun, W., \& De Waal, F. B. M. (2011). Elephants know when they need a helping trunk in a cooperative task. Proceedings of the National Academy of Sciences of the United States of America, 108(12), 5116-5121. https://doi.org/10. 1073/pnas. 1101765108
R Core Team. (2018). R: A language and environment for statistical computing [Computer software]. Retrieved from https://www.rproject.org/

Range, F., Möslinger, H., \& Virányi, Z. (2012). Domestication has not affected the understanding of means-end connections in dogs. Animal Cognition, 15(4), 597-607. https://doi.org/10.1007/ s10071-012-0488-8

Rensch, B., \& Dücker, G. (1977). The Solution of Patterned String Problems By Birds. Behaviour, 62(1-2), 164-173. https://doi.org/ 10.1163/156853977X00081

Riemer, S., Müller, C., Range, F., \& Huber, L. (2014). Dogs (Canis familiaris) can learn to attend to connectivity in string pulling tasks. Journal of Comparative Psychology, 128(1), 31-39. https://doi.org/ 10.1037/a0033202

Schuck-Paim, C., Borsari, A., \& Ottoni, E. B. (2009). Means to an end: Neotropical parrots manage to pull strings to meet their goals. Animal Cognition, 12(2), 287-301. https://doi.org/10.1007/ s10071-008-0190-z

Taylor, A. H., Knaebe, B., \& Gray, R. D. (2012). An end to insight? New Caledonian crows can ring-spontaneously solve problems without planning their actions. Proceedings of the Royal Society B: Biological Sciences. https://doi.org/10.1098/rspb.2012.1998

Taylor, A. H., Medina, F. S., Holzhaider, J. C., Hearne, L. J., Hunt, G. R., \& Gray, R. D. (2010). An investigation into the cognition behind spontaneous string pulling in new caledonian crows. PLOS ONE, 5(2). https://doi.org/10.1371/journal.pone.0009345

van Horik, J. O., \& Emery, N. J. (2016). Transfer of physical understanding in a non-tool-using parrot. Animal Cognition, 19(6), 1195-1203.

Wang, L., Luo, Y., Wang, X., Maierdiyali, A., Chang, H., \& Li, Z. (2019). Azure-winged magpies solve string-pulling tasks by partial understanding of the physical cognition. Current Zoology, 65(4), 385-392. https://doi.org/10.1093/cz/zoy070

Wasserman, E. A., Nagasaka, Y., Castro, L., \& Brzykcy, S. J. (2013). Pigeons learn virtual patterned-string problems in a computerized touch screen environment. Animal Cognition. https://doi.org/10. 1007/s10071-013-0608-0

Werdenich, D., \& Huber, L. (2006). A case of quick problem solving in birds: String pulling in keas, Nestor notabilis. Animal Behaviour, 71(4), 855-863. https://doi.org/10.1016/j.anbehav.2005.06.018

Witt, A., \& Luke, Q. (2017). Guide to the naturalized and invasive plants of Eastern Africa. In A. Witt \& Q. Luke (Eds.), Guide to the naturalized and invasive plants of Laikipia. CABI. Nairobi, Kenya. https://doi.org/10.1079/9781786392145.0000

Publisher's note Springer Nature remains neutral with regard to jurisdictional claims in published maps and institutional affiliations. 